\title{
التسويق الريادي وأثره في استراتيجيات بورتر التنافسية: مدخل في مدى ادراك مديري المشاريع الصغيرة والمثوسطة الحجم لثلك العلاقة \\ (دراسة ميدانية لأراء عينة من مديري عدد من المشاريع الحدمية في محافظة دهوك)

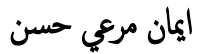 \\ احسان محسن حسين

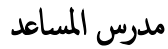

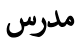

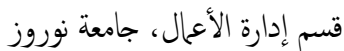 \\ اقليم كردستان العراق \\ قسم إدارة الأعمال، جامعة نوروز \\ اقليم كردستان العراق
}

المستخلص

سعت الدراسة الحالية المى التعرف على مدى إدراك مديري المشاريع الصغيرة والمتوسطة الحجم لمفهوم التسويق الريادي واستراتيجيات بورتر التنافسية والعلاقة بينها، ونظراً لأهمة القطاع الخدي فقد اجريت الدراسة في عدد من المشاريع الخدمية الصغيرة والمتوسطة الحجم في محفظة دهوك، إذ تم الحصول على البيانات اللازمة للجانب الميداني من خلال استمارة الاستبيان التي تم توزيعها على عينة من مديري المشاريع الصغيرة والمتوسطة الحجم مؤلفة من (50) مدير مشروع. وتوصل البحث الى بموعة من الاستنتاجات أهما وجود علاقة ارتباط وأثر معنوية بين التسويق الريادي واستراتيجيات بورتر العامة على المستوى الكلي والجزئي، ثم اختم البحث بمجموعة من التوصيات اهمها زيادة الاهتام بمفوم التسويق الريادي واستراتيجيات بورتر العامة بشكل متكمل من أجل تحقيق أداء متميز على مستوى الأعال للمشاريع

$$
\text { والبحث عن حالة التفرد في قيادة السوق. }
$$

الكلمات المفتاحية للبحث: المشاريع الصغيرة والمتوسطة ، التسويق الريادي ، استراتيجيات بورتر التنافسية

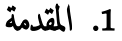

تُعد المشاريع الصغيرة والمتوسطة محركاً اساسياً لخلق فرص العمل والنمو الاقتصادي في مجال اعال او صناعة معينة، وتنبي المنظمة مزاياها التنافسية عندما تنفذ خطوات الدول المتقدمة والنامية على حدِ سواء، كما يتضح من مساهتها في التنوع الاقتصادي تكنها من الحصول على مزايا افضل من المنافسين لجذب الزبائن وذلك بتحقيق قيمة وتنمية القطاع الخاص (Abdelrahman,2010,12)، فرغبة المشاريع الصغيرة للزبون وبشكل متميز عن المنافسين، فقد توجهت المشارع الخدمية إلى بناء والمتوسطة في ان تكون في المقدمة ياتي من خلال استثارها لكل الفرص المتاحة اماهما استراتيجيات تنافسية تستطيع من خلالها الوصول المى اهدافها اعتماداً على معرفتها او توليد فرص قد تكون معدومة لدى المشاريع الاخرى (المنافسين)، لذا يعد بالاسواق المستهدفة من حيث خصائص المستهلكين والمنافسين ثم اختيار البديل التسويق الريادي من المواضيع المهمة في الوقت الحاضر الذي ستمثل في استثار الفرص الاستراتيجي الافضل(قيادة الكلفة- التمايز- أوالتركيز) وصولاً المى المزايا التنافسية وتحمل المخاطر والابداع والميل الى الاستباقية والتركيز على الزبائن لتحقيق مزايا المرغوبة. وتحتيقاً لما تقدم فقد شمل هيكل البحث المحاور الأتية( الجانب المنهجيتنافسية تمكنها من الثفوق على المنافسين عن طريق تحديد الكيفية التي تتنافس في الجانب النظري للتسويق الريادي واستراتيجيات بورتز العامة وكذلك تضمن البحث الجانب الميداني متمثل بالوصف والتشخيص وكذلك علاقات الارتباط والثأثير واخيراً 
وضع المرتكزات النظرية لمفهوم التسويق الريادي واسترتيجيات بورتر التنافسية. التعرف على طبيعة الأرتباط والأثر بين التسويق الريادي واسترتيجيات بورتز التنافسية على وفق تصورات عينة البحث.

التحقق من ادراكـ مديري المشايع الصغيرة والمتوسطة لمفهوم التسويق الريادي واسترتيجيات بورتز التنافسية.

وضع عدد من التوصيات ذات العلاقة بموضوع البحث بهدف الاسهام في تطوير عمل

$$
\begin{aligned}
& \text { المخطط الفرضي للبحث الصغيرة والمتوسطة الحجم. }
\end{aligned}
$$

تضمن مخطط البحث عدداً من المتغرات، حيث أن التسويق الريادي يمثل المتغير مستقل، في حين أن استراتيجيات برورتر التنافسيةكتغير معتمد بابعاده ( قيادة

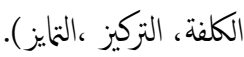

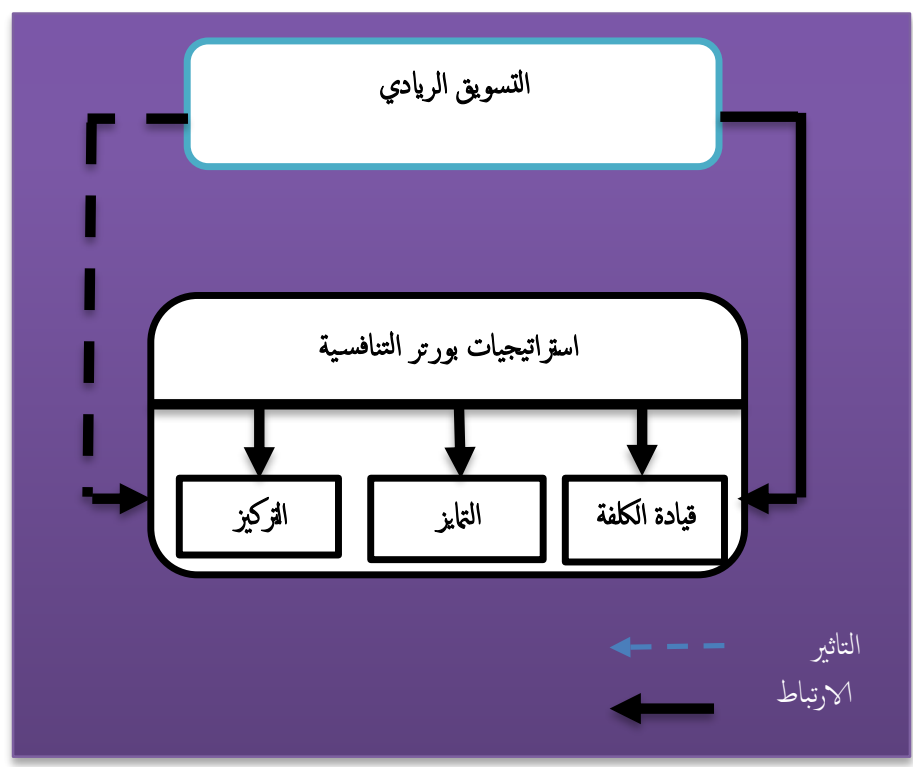

الشكل(1) تخطط البحث الافتزاضي

المصدر: اعداد الباحثان

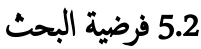
في ضوء مشكلة البحث واهدافه تم تبني الفرضيات الاتية والتي سيتم اختبارها عند

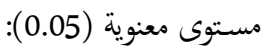

على الرغ من اهية المشاريح الصغيرة والمتوسطة الحجم ودورها في معالجة بعض الاختلالات الاقتصادية إلا أن الاحصاءات العالمية تشير الى ان 50\% منها تفشل خلال السنوات الاولى والثانية من تاريخ الانشاء وان 20\% منها تستطيع الصمود خلال السنوات الحمسة الأولى من حياتها (Manu and Nelson,2000,30)، وذلك لما تعانيه من نقاط ضعف وتحديات إدارية ومالية وتسويقية، لذا جاء الغرض من هذه الدراسة في التعرف على مدى ادراك المشاريع الصغيرة والمتوسطة لمفوم التسوبق الريادي واستراتيجيات بورتر التنافسية والعلاقة بنهها، ويكن تحديد مشكلة الدراسة عن طريق الإجابة على التساؤلات الآتية: ما مدى إدراك مديري المشاريع الصغيرة والمتوسطة لمفهوم التسويق الريادي واستراتيجيات بورتز التنافسية ؟ هل توجد علاقة ارتباط بين التسويق الريادي و واستراتيجيات بورتر التنافسية المتثثلة بـ( قيادة الكلفة- التيز- التزكيز) للمشاريع الصغيرة

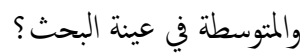

هل توجد علاقة أثر بين التسويق الريادي واستراتيجيات بورتز التنافسية المتمثلة بـ قيادة الكلفة- التمايز - التركيز) للمشاريع الصغيرة والمتوسطة في عينة

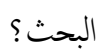

\section{2}

تاتي اهمية البحث من اهمية التسويق الريادي والدور الذي يلعبه في تعزيز تنافسية المشاريع الصغيرة والمتوسطة، حيث يعد موضوع التسويق الريادي أساساً للمنظلات نخو استغلال الفرص التسويقية التي تبحث عنها بالتفكير والعمل على تقديم السلع والخدمات التي يرغبها الزبائن والتي تشكل فرصاً غير مستثمرة من قبل المنظمات الاخرى،آخذا بنظر الاعتبار الخخاطر المتتبة على ذلك من خلال الابداع في العمليات التسويقية واستغلال الموارد بافضل صيغة مككنة والتي تؤدي إلى قدرة المنظمة على استقراء المستقبل والعمل على استغلال الفرص الممكنة المى اقصى حد. 
7.2 اداة البحث

من اجل التوصل الى حل مشكلة البحث واختبار فرضياته قام الباحثان بتطوير

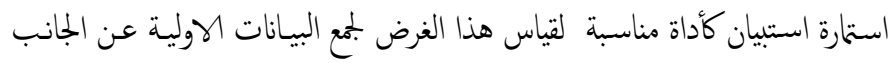

$$
\text { الميداني. }
$$

$$
8.2 \text { حدود البحث: تثثلت حدود البحث بالاتي: }
$$

الحدود المكانية: ثمل البحث عدد من المشاريع الصغيرة والمتوسطة الحجم

$$
\text { العاملة في قطاع الخدمات في محافظة دهوك. }
$$

الحدود الزمانية: انحصرت الفترة الزمنية من تاريخ 2019/4/1-2018/11/1

الحدود البشرية: تمثلت بمديري المشاريع الصغيرة والمتوسطة الحجم.

\section{3. الهطار النظري/ التسويق الريادي}

1.3 مفهوم التسويق الريادي

ظهر مفهوم التسويق الريادي لوصف النشاطات التسويقية للمنظلات الصغيرة والمتوسطة ، ولما كان الأمر كذلك فقد تطور التسويق الريادي ضمن ميادين جديدة وواعدة ، في حين أن تحليل التسويق في المنظات الصغيرة والجديدة يكون مسالة همة في ضوء الحصة الكبيرة من النشاطات الاقتصادية التي بالامكان أن تُنسب الى هذه Kraus, et.al, ) الانواع من المنظات (Kraus, et.al, 2009: (بيرى الباحثان ان هناك مدخلين مختلفين التسويق 27 (2011) 27 (Morris, et.al, 2002: 8)

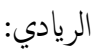

المدخل الاول: ينظر إلى التسويق الريادي كتسويق خاص بالمنظات الصغيرة التي تتميز بحجم المنظمة وعمها. المدخل الثاني: ينظر الهيا على انها الاستباقية وتحديد واستغلال الفرص بالاعتماد على الابداع واخذ الخخاطرة والانشطة التسويقية غير الخخططة. وكلاها يحاولان تعريف التسويق الريادي وقد يكونان وبحين لعملة واحدة لأن الخصائص النوعية (الصغر والحداثة) يبدوان السياقات التي تفضل نشاطات التسويق المدفوعة بالريادة، أي الابداع والتوجه نخو المخاطرة والروح الفاعلة. ومصطلح التسويق الريادي جاء لوصف النشاطات التسويقية المتحققة في الممارسات الجريئة والجديدة بذات الوقت ومن خلال المنظات التسويقية المختلفة، وهذا التوجه المعاصر في التسويق من شأنه أن يسهم إلى حد كبير في تنمية حالة الابداع والنمو الاقتصادي لكونه قائم على الولوج بالاعال
أ. الفرضية الرئيسة الأولى: "يوجد ارتباط معنوي ذي دلالة احصائية بين التسويق الريادي و واسترتيجيات بورتر التنافسية على المستوى الكلي في المشاريع الصغيرة والمتوسطة عينة البحث". وقد تفرعت عنها الفرضيات الفرعية الآتية: الفرضية الفرعية الأولى: يوجد ارتباط معنوي ذي دلالة أحصائية بين التسويق

$$
\text { الريادي و قيادة الكلفة للمشاريع الصغيرة والمتوسطة عينةالبحث. }
$$

الفرضية الفرعية الثانية: يوجد ارتباط معنوي ذي دلالة أحصائية بين التسويق الريادي والتركيز للمشاريع الصغيرة والمتوسطة عينة البحث..

الفرضية الفرعية الثالثة: يوجد ارتباط معنوي ذي دلالة أحصائية بين التسويق الريادي و التزيز للمشاريع الصغيرة والمتوسطة عينة البحث. ب. الفرضية الرئيسة الثانية: يوجد تأثير معنوي ذي دلالة احصائية للتسويق الريادي في استراتيجيات بورتر التنافسية على المستوى الكلي في المشاريع الصغيرة والمتوسطة عينة البحث". وقد تفرعت عنها الفرضيات الفرعية الآتية: الفرضية الفرعية الأولى: يوجد ثأثثر معنوي ذي دلالة احصائية للتسويق الريادي في قيادة الكلفة للمشاريع الصغيرة والمتوسطة عينة البحث. الفرضية الفرعية الثانية: يوجد تأثير معنوي ذي دلالة احصائية للتسويق الريادي في التزكيز للمشاريع الصغيرة والمتوسطة عينة البحث. الفرضية الفرعية الثالثة: يوجد تاثير معنوي ذي دلالة احصائية للتسويق الريادي في التمايز للمشاريع الصغيرة والمتوسطة عينة البحث.

\section{2 مجتمع البحث وعينة}

يتكون مجتمع البحث من المشاريع الخدمية الصغيرة والمتوسطة الحجم العاملة في قطاع الخدمات في محفظة دهوك والمسجلة في صندوق دع المشاريع الصغيرة للشباب/ مكتب دهوك التي يبلغ عددها (628) مشروعاً خدي لغاية 2016 ، واختار البحث العينة وفقاً لمقتضيات البحث اذ ان التسويق الريادي واستراتيجيات بورتر تقع على عاتق صناع القرار في المشاريع الصغيرة والمتوسطة الحجم ومن هنا جاء اختيار عينة البحث المنكونة من مديري المشاريع بوصفهم صانني القرارات ومتخذيه اذ بلغ حجم العينة (50) مديراً وهم يشكلون سبة (7.9\%) من مجتع البحث. 
ترتبط قرارات التسوبيق الريادي بالاهداف الشخصية ( شخصية الريادي المنظمي ) وباداء المنظمة الطويل الاجل . يؤدي إلى اختيار الطرائق المرنة القابلة للتعديل وفقاً لطلب الزبائن ( الشخصنة التسويقية ) . يقوم بالاستجابة السريعة للتحولات في اذواق الزبائن . يبحث عن البيانات التسويقية الملائمة وخاصةً الصغيرة منها التي يغفل عها الكثير

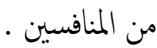

يبني معرفة الزبائن عن طريق التفاعلات والاحداث التي تحدث في السوق . يقوم على الغاء بعض الخطوات الزائدة في العمليات التسويقية من اجل السرعة

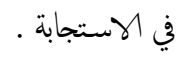

يتم وضع الرؤى والاستراتيجيات التسويقية من خلال الخطوات التكتيكية التي قامت بها المنظمة والتي اوصلتها الى الهدف المطلوب ( اي تعديل الرؤى والاستراتيجيات في ضوء التغيرات التسويقية) . يبني القرارات التسويقية من خلال البيانات والمعلومات الواردة من خلال الاتصالات اليومية وانظمة المعلومات الختلفة في المنظمة .

يحاول التسويق الريادي تقليل اهمية البحوث الرئيسة والاساسية للسوق والعمل على تفعيل بحوث السوق غير الرسمية والتي تعمل على ايجاد الفرص غير

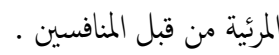

يركز على الابداع والابتكار واللذين يعتبران من عوامل نجاح اسواق المنظمة

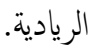
يركز على عمليات البيع والدع والتشجيع لمنتجات المنظمة.

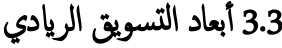

بما أن المنظمات المعاصرة تعمل في بيئة غير مستقرة وتشهد تغيرات هائلة في العديد من القطاعات الاقتصادية والاجتاعية والتكنولوجية والسياسية والقانونية والتنافسية، ليس اماما إلا أن تنني علاقات طويلة الامد مع الزبائن والمحافظة عليهم من خلال ابعاد التسويق الريادي (Bjerke \& Hultman, 2002:295)، وبما أن ابعاد التسويق الريادي في اغلب الاحيان تكون مرتبطة بالمنظات الصغيرة والمتوسطة
- الجديدة والمبتكرة ولا يقتصر القيام بهذا العمل على المنظلات الكبيرة في السوق فسب، بل أنه يشمل المنظلات الصغيرة وايا كان حجمها طالما كانت لديها القدرة على الدخول بأنشطة جريئة ونابحة في مجال التسويق، وذلك نظراً لقربها من الاسواق وقدرتها على تلمس حاجات الزبائن ورغباتهم بشكل اكثر دقة(البكري، 2014، 186)، وعلى وفق هذا المنظور يعرف التسويق الريادي بأنه استثمار واستغلال الفرص السوقية من اجل كسب الزبائن المربحين والمحافظة عليهم من خلال تنبي المداخل الابتكرية والابداعية في ادارة الخخاطر ومداخل الرفع للموارد ومداخل تحتيق التمية الجاذبة للزبائن والقادرة على الاحتفاظ بهم كزبائن دائمين مربين(صادق، 2010،5). وقد عرف من قبل(Jones \& Rowley,2011:30) بأنه تبنى جوانب من السلوكيات التي تم بثثا بشكل تقليدي في الريادة والابداع ، وفي مجال مشاركة الزبائن والعلاقة معهم .كما عرف من قبل (اوسو،2012،29 ) بأنه تحديد الفرص

- التسويقية واستغلالها، واستخدام الطرق الجديدة التي تعتمد على التميز والتنويع في البرامج التسويقية المقدمة إلى الزبائن لاضافة قيمة إلى المنتجات التي تقدما المنظمة، وكذلك الموارد والمهارات اللازمة لها ، ومن ثم الحصول على المكافئة الناتجة عنها. ويرى الباحثان بأن التعريف الاجرائي للتسويق الريادي يتمثل في الاستباقية في تحديد او استغلال الفرص للحصول على الزبائن المربين والاحتفاظ بهم من خلال اساليب مبتكرة لادارة الخخاطر واستغلال الموارد وخلق القيمة.

\section{3 سمات التسويق الريادي}

يعتقد البعض أن التسويق الريادي هو عبارة عن هيكل يتميز بسات الابنكار

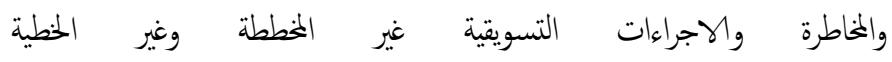
(Kolongahapitiva,2018:46)، فالكثر من النشاطات الريادية مثل تماثل وتطابق واستخدام التقنيات لغرض الابداع والابتكرر وتحديد الفرص الجديدة ، والقدرة على الوفاء لمتطلبات واحتياجات الزبائن ، يككن ان تكون ايضا مظهر من المظاهر الاساسية والرئيسة للتسويق الريادي (Dwyer,2009:1) ، وقد حدد الباحثان (Hills \& Hultman, 2006:222) عددا من الصفات للتسويق الريادي، يخترق ويتغلغل في جميع المستويات والمجالات في المنظمة . 


\subsection{3 توليد القيمة: Value creation}

ان النقطة المحورية للتسويق كانت في الماضي تنتمثل في المعاملة، أما الأن فتتمثل في العلاقة وان النقطة الجوهرية في التسويق الريادي هي توليد قيمة مبتكرة على افتراض ان توليد القيمة هو شرط اساسي من اجل المعاملات والعلاقات، فهمة المسوق تتمثل في اكتشاف المصادر غير المستقلة لقيمة الزبائن وانشاء بمحوعات فريدة من الموارد لانتاج القيمة(Nwaizugbo \& Anukam,2014:95). ويعتبر الزبون من الموجودات المهمة الذي تزيد قيمنه في المنظلات التي تتبنى عمليات التسويق الريادي ، وأن تقسيم الزبائن يعتمد بشكل كير على الفتزة الزمنية لقيمة هؤلاء الزبائن والتي تعتبر من الطرق الفعالة لاستهداف هؤلاء الزبائن لأن انشطة المزيج التسويتي تهدف اساساً

الى تعزيز قيمة الزبون (Ho, et.al, 2006:2).

Innovativeness : 4.3.3

إن الابداع يمثل توليد وظهور فكرة أو منتج أو خدمة أو عمليات أو مخرجات أو سياسات أو ادوات أو ابهزة جديدة يكن تبنيها من العاملين في المنظمة بدع من الادارة العليا فيترتب عليها احداث نوع من التغيير في بيئة المنظمة (الكلكاوي،2004،21).فالابداع التسويقي يعنى بوضع الهفكار الجديدة أو غير التقليدية موضع التطبيق الفعلي في النشاطات التسويقية، وقد يركز على المنتج سواء كان سلعة أو خدمة أو السعر أو الترويم أو التوزيع أو على كل هذه الابعاد في آن واحد، وبمعنى اخر هذا النوع من الابداع يوجه الم ابعاد المزيج التسويتي مجتمعة معاً

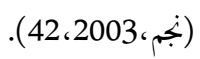

\section{Risk Taking : 5.3.3 اخذ المخاطر:}

يتمثل هذا البعد في رغبة الإدارة للتعامل مع موارد غير ثابتة للحصول على فرص لحقيق ماهو غير أكيد أو مشكوك فيه، وفي السياق نفسه أن تحمل المخاطرة تعني الأستعداد لاتخاذ موقف جرئ كالدخول في أسواق تتحمل قدراً من المخاطرة، ولكي تتمكن المنظمة من الخصول على عوائد مالية كيرة يجب عليها ان تتحمل هذه الخخاطرة ولاسيا اقتراض رؤوس الأموال، تقديم سلع وخدمات جديدة للأسواق والأستثمار في التقنيات

المكتشفة(شريف ،2015،115).

Proactiveness : 6.3.3 تتصف الاستباقية التسويقية بالقدرة على استباق الفرص أو توقعها، والكشف عن الاتجاهات المستقبلية للزبائن، وفي ظل الاستباقية التسويقية تعمل المنظمة بشكل
الحجم، لذا فانه من المفيد أن نقول بأنه بامكان المنظمات الكبيرة أن تعمل بغعالية على رفع قدرة ابعاد التسويق الريادي لاجل تحقيق الميزات التنافسية ، لأن هذه المنظلات الكبيرة التي تتبنى ابعاد التسويق الريادي تنخرط في العمليات التسويقية التي تؤكد او تركز على تكوين الامكنيات او اكتشافها ، والاستفادة منها. وهكذا فان المنظمة لن تعمل على الابداع كي تشبع الحاجات الواضحة للزبائن الحاليين فسب بل ستعمل ايضاعلى تحتيق قيمة المنتجات المبدعة والعمليات والاستراتيجيات ومجالات المشاريع التجارية بهدف النكوين والتقييم والاستفادة من امكانات السوق الجديدة لاجل اشباع الحاجات الكمنة لجموعة الزبائن الموجودين والجدد (صادق، 2010، 11-12). ويكن تحديد أبعاد التسويق الريادي على وفق الآتي:

\section{Resource-Leveraging : 1.3 .3}

يرى (Mehran \& Morteza,2013:301) احدى التحديات الرئيسة للتسويق في المشاريع الجديدة هو ندرة الموارد المالية والبشرية، هذه الندرة تتطلب مراقبة صارمة لتكليف التسويق وتثيد نطاق وكثافة الانشطة التسويقية التي يكن للمشروع الجديد ان يتابعها ويمكن لرجال الاعمال اما التخفيف من هذه المشكلة بالحصول على موارد اضافية مثل راس المال الاستثاري او القروض المصرفية بتحقيق اقصى تاثير لهذه الموارد النادرة، ويرى(سعيد،2011،129) إن رفع قيمة الموارد هي العملية التي تقوم بها المنظات التي تتبع ابعاد التسويق الريادي وفقا لمواردهم الخاصة لتحليلها والتاكد من الموارد التي تحتاج اليها تلك المنظات، و بالتالي تحديد تلك الموارد التي تتطلها المنظمة ورفع قيمها.

\section{Customer-Focus 2.3.3 التركيز على الزبون}

تنصب الكثير من الانشطة في التسويق الريادي على اساس معرفة توجحات الزبائن بشكل دقيق وذلك لصياغة العمليات التسويقية واتخاذ القرارات وبما يقود الى تحقيق التوافق مع تلك الجهات، وذلك بالتزكيز على الميزة التنافسية التي تمتلكها المنظمة وبما يعزز من موق منتجاتها في السوق التنافسي. هذا يعني معرفة توجهات الزبائن لاتنحصر في حدود اعالها الحالية وفي اسواقها التي تعمل بها، بل انها تتركز ايضا وبشكل جوهري نخو زبائها الحمتلين والاسواق الجديدة التي يمكن ان تدخل الهيا المنظمة لاحقا (البكري،2014،193)، وهذا ما يقود إلى دقة التوجه نحو الزبائن المستهدفين ولتقديم منتجات تتوافق مع حاجاتهم ورغباتهم وبشكل ميز عن المنافسين. 
المتنافسين ورسالة، وأن المنظات ذات النشاط المنفرد التي تعمل في صناعة واحدة تعد وحدة أعلال بسبب كينونتها واهدافها، وتتبنى استراتيجيات تهدف إلى تحسين المركز التنافسي لها لتحقيق اقصى الارباح (السكارنة،2015،266)، ومن الجدير بالذكر أنه قد اضيفت تحويرات همة للاستراتيجيات الثلاث، وذلك بفعل التطورات التكنولوجية وزيادة حدة المنافسة حيث لم تبق البدائل الاستراتيجية للمنظمة محصورة بثلاث خيارات، حيث تطورت اساليب المنافسة واخذت منحنى جديد بتنوع واسع، فعلى سبيل المثال لم يبق خيار التميز بالنوعية مرتبطاً بالسعر المرتغ، انما تعمل بعض رِ المنظات على تحسين النوعية مقابل اسعار منخفضة نسبيا قياسا بالمنافسين، إن تكمل استراتيجية الكلفة المخفضة والتمييز تشير إلى قيام منظمة الاعمال ببناء ميزاتها التنافسية من خلال تخفيض النكليف وانجاز مستويات عالية من التميز وبشكل اني.(بن حمدان وادريس،2007،241)، وانطلاقا مما تقدم ركز البحث على ثلاث استراتيجيات تنافسية تمثلت بالآتي:

\section{4 استراتيجية قيادة الكلفة Cost Laedership} ينبغي عدم الخلط بين النكلة المنخفة والسعر المنخفض،فالمنظمة التي لها تكاليف منخفضة ربما تمرر أو لاتمرر هذا التوفير إلى الزبائن، إنا يكنها بدلاً من ذلك استخدام هذا الوضع بالاضافة إلى ضوابط تكليف مشددة وهوامش منخفضة لتشييد حاجز فعال امام الآخرين الذين يفكرون إما في دخول السوق وإما توسيع تغلغلهم فيه، ويكن تحقيق الكلفة المنخفضة عن طريق الانشطة الرئيسة المتمثلة بالكفاءات التشغيلية، واعادة تصميم المنتج، والتوحيد القياسي للمنتج، ووفورات الحجم (بارو،2018،56).وأن هذه الاستراتيجية تركز عل تحقيق الكفاءة، باعتمد ثلاثة ابعاد تنمثل بالآتي(Josiah\&Nyagara,2015:2) : البعد الوول: يتثل في انتاج كميات كيره من المنتج،ويعني أن النكليف الثابتة موزعه علي عدد اكبر من وحدات المنتج او الخدمة ، مما يؤدي الى انخفاض نكلفه الوحدة ، اي أن المنظمة تأمل في الاستفادة من وفورات الحجم واثار منحني الحبرة، بالنسبة للمُنظلات الصناعية ، يصبح الانتاج الضخم استراتيجية وغاية في حد ذاته، فستويات الانتاج الاعلى تتطلب وتؤدي إلى ارتفاع حصة السوق، وتخلق حاجز دخول للمنافسين المحتمين ، الذين قد يعجزون عن تحقيق مضاهاة التكليف والاسعار المنخفضة للمُنظلات.
مبكر على استغلال الفرص قبل المنافسين، وهكذا يكنها أن تكون في وضع و مركز لاظهار اداء متفوق على المنافسين، وتميل المنظمة إلى تشكيل بالبيئة في صالحها وتعمل على الاستباق في تلبية احتياجات الزبائن و مواكبة النغرات البيئية، أو المشكلات التي قد تحدث في المستقبل (Bonnet \& Le par,2008:9).

Opportunity Focus 7.3.3 التركيز على الفرص ييعد التعرف على الفرص وتحقيقها من الانشطة التسويقية المهمة لنجاح المشاريع الصغيرة والمثوسطة الحجم، ويتم تثييم امكنات السوق بشكل عام حسب درجة الملائمة بالنسبة لقدرات وموارد المشروع، وهذه تبين قدرة المشروع على اختيار الفرصة الصحيحة التي تحدد النجاح (Nwaizugbo \& Anukam,2014:95)، 4. استراتيجيات بورتر التنافسية تحقق المنظمة مزايا تنافسية تمكنها من التفوق على منافسيها، عن طريقها تتحدد الكيفية التي تتنافس بها في مجال الأعمال أو صناعة معينة، وتبني المنظمة مزاياها التنافسية عندما تتخذ خطوات تمكنها من الحصول على مزايا افضل من منافسيها لجذب الزبائن وذلك بحقيق القيمة للزبون وبشكل متميز عن المنافسين( ادريس والغالبي،2016،105)، فالاستراتيجية على مستوى الاعمال تتعلق بالحيارات التي تتخذها الادارة من اجل المنافسة في السوق فهي بمحوعه متكملة ومنسقه من الالتزامات والاجراءات التي تستخدها المنظمة لاكتساب ميزه تنافسيه من خلال استغلال الكفاءات الاساسيه في اسواق منتجات محددة (PisanoHitt,2010:3)، كما أن استراتيجيات الاعمال او الاستراتيجيات التنافسية تعد بمثابة خطة العمل التي ينهججها المديرون الاستراتيجيون لاستغلال موارد المنظمة وكفاءاتها المتميزة لاكتساب مزايا تنافسية في سوق او صناعة ويكن القول أن الاستراتيجية على مستوى وحدات الاعمال تهتم بتحديد الميزة التنافسية التي ستنفذها على مستوى كل نشاط. ومادامت كل المنظات لاتتمتع بنفس المزايا أو انها لاتتتلك نفس القدر من الموارد أو ليس لها نفس مستوى الطموحات فهي لن تخظى بنفس الإمكانيات التنافسية (مقري ويجياوي،2015،87).كما أن دراسة جوانب القوة والضعف في المنظمة تهدف اساساً إلى محاولة زيادة قدرتها على المنافسة في الاسواق التي تعمل بها، والسؤال المهم هنا هو كيف يمكن للمنظمة أن تحول جوانب القوة والضعف لدها إلى مزايا تنافسية تستطع من خلالها أن تواجه المنظات المنافسة في الاسواق، كما يذكر بأن وحدة الاعحال هي نظام فرعي للمنظمة، تمتلك منتجاً معيناً وسوقاً معيناً ومجموعة من 
نوعه، ويكن تحقيق هذه الاستراتيجية بعدة طرق على سبيل المثال طريقة التصميم، صورة العلامة التجارية، التكنولوجيا المستخدمة، المميزات، طريقة تقديم خدمة الزبائن ، ويكن تصنيف قواعد التايز الى ثلاث فئات هي(Minarik,2007:17) : لتحقيق التمايز قد تزكز المنظمة مباشرةً على مميزات المنتج نفسه كتعقيد وبساطة

$$
\text { المنتج، توقيت تقديم المنتج، الموقع. }
$$

قد تركز المنظمة على العلاقة بينها وبين زبائها على سبيل المثال تخصيص السلع

$$
\text { والخدمات للزبائن ، والتسويق لسمعة المنتج. }
$$

يككن تحقيق التايز عن طريق التزكيز على العلاقات داخل المنظمة والتي تشمل

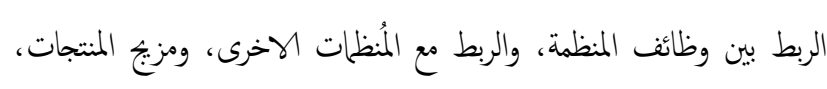

$$
\text { ودع قنوات التوزيع. }
$$

كما تمثل استراتيجية التيايز بعرض المنتجات باسعار اعلى من اسعار السوق، ولتحقيق ذلك فانه يتم عرض السلع العصرية في بيئة انيقة وجذابة، خلافاً لمتاجر المنافسين في السوق، ولتكون قادرة على عرض احدث المنتجات وآخر الصيحات للزبائن وعروض خدمات مابعد البيع واثناء الاستخدام، فان المنظمة تركز على الترويج عن طريق نقل افضل صورة عن المنتج إلى الزبون، بحيث يصبح هدف الزبون هو العلامة التجارية

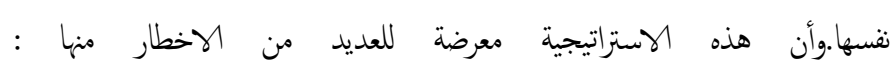

(Minarik,2007:17)

أ- زيادة التكلفة مقارنة بالمُظظات الاخرى التي تنتع بتكليف اقل سيؤدي إلى تقليل ولاء الزبائن للعلامة التجارية وتحولم لثراء علامة تجارية اخرى لانها

$$
\text { ب- خطر تقليد المنتج من قبل المنافسين. }
$$

ت- في حال تخلف المنتجات المتميزة فان المُنظات منخفضة النكلفة سوف تستولي

$$
\text { على حصة السوق الخاصة بالمنظمة المتميزة. }
$$

ويرى الباحثان أن التمايز مهدف إلى كسب عائدات اعلى من المتوسط في الاعمال التجارية لأن الولاء للعلامة التجارية يقلل من حساسية الزبائن تجاه السلع والخدمات، وعلى هذا الاساس يككن تمرير الزيادة في الاسعار على المشتري، كما أن الولاء

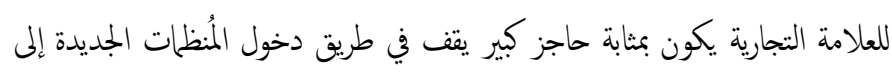
السوق، حيث يتطلب الأمر من المُظظات الجديدة تطوير كفانتها من اجل تمييز
البعد الثاني: يتثثل في تحتيق انخفاض في تكليف التشغيل المباشرة وغير المباشرة، ويتحقق ذلك من خلال تقديم كميات كيره من المنتجات القياسية ، وتقديم المنتجات الاساسيه بدون الرتوش والحد من التخصيص في المنتج والمدمات المقدمة. وتبقي تكاليف الانتاج منخفضه باستخدام مكونات اقل في الانتاج. البعد الثالث: يتمثل في السيطرة على سلسله التوريد/الشراء لضمان انخفاض التكليف، ويكن أن يتحقق هذا بالشراء بالجملة ، والضغط على الموردين في السعر ، وتقديم عروض تنافسيه للاسعار، والعمل مع الموردين للاحتفاظ بمخزون بكميات منخفضة والثراء في الوقت المناسب او المخزون المدار من قبل المورد. إن وضع المنظمة كنظمة مصنعة ومنخفضة النكلفة ، يضع عبئًا ثثيلاً على المنظمة ويجعلها عرضةً لعدد من المخاطر ، منها:Josiah\&Nyagara,2015:2) أ- التغير التكنولوجي والذي سيمحو الاستثمرات السابقة ويتجاوز التعلم الماضي المنظمة. ب- - خطر التقليد من قبل المنظات الاخرى التي تدخل نفس القطاع والتي لدها ميزة التعلم منخفض التكلفة. ت- تقليل الاهتمام باحتياجات وتفضيلات الزبائن بسبب اعتبارات تقليل الكلفة. ث- التضخم غير المتوقع في التكاليف والتي تقلل من قدرة المنظمة على تميز المنتج (جعله يتميز بتكلفة منخفضة) من خلال استراتيجية تخفيض النكلة. ويرى الباحثان بأن استراتيجية قيادة الكلفة هي احدى الحنيارات التي تتطلب بناء الامكانيات التصنيعية ذات الكفاءة العالية والاستمرار في تخفيض النكليف باستخدام الخبرة السابقة والرقابة على الكلف بشكل عام وتقليل النفقات إلى الحد الادنى في مجال البحوث والتطوير وخدمات البيع والتزويج.

\section{4 استراتيجية الثايز Differentiation}

يرى ( ادريس والغالبي،2016،105) بان استراتيجية التزيز هي أن تتمكن المنظمة من تلبية حاجات ورغبات زبانهها بطريقة فريدة، بتقديم منتوجات مبتكرة وذات نوعية عالية، وقد يرتبط ذلك بتقديم خدمات خاصة من اجل أن يكون المشتري مستعد لدفع سعر اعلى. لذا فان مفتاح التزيز هو الفهم العميق لما يريده ويختاجه الزبائن حقاً، والأهم من ذلك إن الزبائن على استعداد للدفع مقابل ما يحتاجونه (بارو، 2018،56)، ويقصد باستراتيجية التايز تميز السلعة او الخدمة التي يقدها المشروع عن بقية السلع والخدمات الموجودة في السوق، بعبارة اخرى هي انتاج شيء ينظر إليه أنه فريد من 
منتجاتها بطريقة أو بأخرى عن المنتجات الموجودة وتحقيق النجاح والتقدم على 5. الجانب الميداني 1.5

المنافسين.

تظهر المعلومات المتاحة في الجدول (1) ننائُ تحليل مجموعة السهات الديموغرافية لأفراد

Focus 3.4 استراتيجية التركيز

عينة البحث في المشاريع المستجيبة، ويكن عرضها على وفق الفقرات الآتية:

تبنى هذه الاستراتيجية في المنظمة على التزكيز على عدد قليل من قطاعات السوق، الجنس: تشير ننائُ توزيع أفراد العينة حسب سمة الجنس إلى أن أغلبية الأفراد هم من

• وتسمى بالاستراتيجية الماصة (المتخصصة) وتتضمن تركيز جهود التسويق على واحد الذكور الذين بلغت نسبته (76\%)، وكانت نسبة الإناث (24\%)، وهذا يشير إلى

أن أغلية المشاريع المستجيبة تشغل الذكور فيها مناصب قيادية أكثر من الإناث. او اثنين من القطاعات الفرعية في السوق عن طريق تكييف المزيج التسويقي للمنظمة بحيث يلبي احتياجات الزبائن في السوق المستهدفة بشكل افضل، حيث تتطلع العمر: تبين أن الفئات العمرية الأولى والثانية المتثثلة بكل من (18-30سنة) والفئة (31-40سنة) سجلت ما نسبته (92\%) من بمحوع أفراد العينة وشكلت أغلبية العينة، أما الفئة العمرية(45 فأكثر) فنكلت النسبة المتبقية من العينة هذا يدل على ان غالبية اصحاب المشاريع الصغيرة والمتوسطة الحجم من متوسطي الاعمار ولديهم خبرة في إدارة مشاريعهم.

المؤهل العلمي: تشير نتائُ وصف العينة من حيث المؤهل العلمي إلى أن حملة شهادة البكالوريوس كونت أغلبية العينة بنسبة بلغت (58\%)، أما حملة الشهادة ثانوية فأقل فجاءت بنسبة بلغت (30 \%) لكل منها، وجاءت بنسبة (12\%) حملة شهادة الدراسات العليا. وبذلك يشير توزيع أفراد العينة على وفق هذه السمة إلى أن أغلبية أفراد العينة تمتلك المؤهلات العلمية والأكاديمة لأداء المهام القيادية في المشاريع المستجبية. عدد سنوات الحبرة في المثاريج: يتضح من نتائُ التحليل من حيث عدد سنوات الخبرة في مجال العمل بالمشاريع أن أغلبية أفراد العينة يتوزعون ضمن ست الفئة (4 - 6سنة) والفئة (7- 9سنة) بنسبة بلغت (70\%) لكل منها، أما فئة (1 - 2 سنة) جفاءت بالمرتبة الأخيرة بنسبة بلغت (10\%)، وتوزعت الفئات الأخرى بين تلك النسب. الجدول (1) السهات الديوغرافية لأفراد العينة

\begin{tabular}{|c|c|c|c|}
\hline النسبة المثوية & العدد & الفنات & السهات \\
\hline 76 & 38 & ذكر & \multirow{2}{*}{ الجنس } \\
\hline 24 & 12 & أنثى & \\
\hline 26 & 13 & 18 - 30 سنة & \multirow{3}{*}{ العمر } \\
\hline 66 & 33 & 31 - 40 سنة & \\
\hline 8 & 4 & 45 سنة فاكَثر & \\
\hline 30 & 15 & ثانوية فأقل & المؤهل العلمي \\
\hline
\end{tabular}
ب- قد تختني الشريحة المركز عليها من قبل المنظمة فقد تكون شريحة غير دائمية في

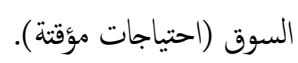
ت- قد تؤدي زيادة التكلة الى تحول الزبائن نحو المُنظات المنافسة ذات المنتوجات الواسعة (الخيارات الواسعة). 
الكلفة التي تمثل النكرارات والنسب المئوية والأوساط الحسابية والانحرافات المعيارية ذات الصلة بالفقرات (Y-Y $)$ التي تميل نحو الاتفاق على توفر هذا البُعد لدى المشاريع المستجيبة، وتشير النسب إلى أن (83.33 \%) من أفراد العينة لدهيم اتفاق على مضمون العبارات (Y-Y هذا التوجه فبلغت (9.33 \%)، وكانت نبة الحياد (6.66 \%)، وجاء هذا بوسط حسابي مقداره (2.77) وانحراف معياري مقداره (0.53). وهذا يعطي دلالة أولية على أن آراء أفراد العينة متفقة على أن المشاريع المستجيبة تعتمد مجموعة من الاجراءات في قيادة الكلفة تيتثل بخفض كلفة المدمات لكسب رضا الزبائن وخفض الاسعار ومقارنة نفقات الترويج مع المنافسين. الجدول (3) وصف بعد استراتيجية قيادة الكلفة

\begin{tabular}{|c|c|c|c|c|c|c|c|c|}
\hline \multirow{3}{*}{ المعياري } & \multirow{3}{*}{ الحسابي } & \multicolumn{6}{|c|}{ مقياس الاستجابة } & \multirow{3}{*}{ الرمز } \\
\hline & & \multicolumn{2}{|c|}{ ل ل لاتفق } & \multicolumn{2}{|c|}{ محايد } & \multicolumn{2}{|c|}{ أتفق } & \\
\hline & & $\%$ & ت & $\%$ & ت & $\%$ & ت & \\
\hline 0.60 & 2.72 & 12 & 6 & 8 & 4 & 80 & 40 & Y1 \\
\hline 0.36 & 2.90 & 6 & 3 & 2 & 1 & 92 & 46 & Y2 \\
\hline 0.64 & 2.70 & 10 & 5 & 10 & 5 & 80 & 40 & Y3 \\
\hline 0.53 & 2.77 & \multicolumn{2}{|c|}{9.33} & \multicolumn{2}{|c|}{6.66} & \multicolumn{2}{|c|}{83.33} & المكؤشر \\
\hline
\end{tabular}

المصدر: إعداد الباحثان بالاعتاد على ننائُ التحليل الأحصائي

ب- بعد استراتيجية الثايز: تشير نتائُ التحليل المذكورة في الجدول (4) إلى إجابات أفراد العينة في المشاريع المستجيبة تجاه وصف بعد التمايز لاستراتيجيات بورتر العامة التي تمثل التكرارات والنسب المئوية والأوساط الحسابية والانحرافات المعيارية ذات الصلة بالفقرات (Y-Y $)$ التي تميل نخو الاتفاق على توفر هذا البُعد لدى المشاريع المستجيبة، وتشير النسب إلى أن (77.33\%) من أفراد العينة لديهم اتفاق على مضمون العبارات (Y, Y (Y)، أما نسبة عدم الاتفاق مع هذا التوجه فبلغت (11.33\%)، وكانت نسبة الحياد (11.33\%)، وجاء هذا بوسط حسابي مقداره (2.66) وانحراف معياري مقداره (0.66). وهذا يعطي دلالة أولية على أن آراء أفراد العينة متفقة على أن المشاريع المستجيبة تعتمد على التمايز في تقديم خدمات ذات جودة عالية مقارنة بالمنافسين وتقديم خدمات استثنائية تبرر ارتفاع الاسعار وتقديم خدمات تلبي حاجات ورغبات الزبائن.

\begin{tabular}{|c|c|c|c|}
\hline 58 & 29 & بكالوريوس & \\
\hline 12 & 6 & دراسات عليا & \\
\hline 12 & 6 & 3-3 سنة & \multirow{4}{*}{ سنوات الحبرة في } \\
\hline 20 & 10 & 4 - 6 سنة & \\
\hline 50 & 25 & 7 - 9 سنة & \\
\hline 18 & 9 & 10 سنوات فاكثر & \\
\hline$\% 100$ & 50 & & الجمموع \\
\hline
\end{tabular}

تشير نتاجُج التحليل المذكورة في الجدول (2) إلى إجابات أفراد العينة في المشاريع المستجيبة تجاه وصف متغير التسويق الريادي التي تمثل النكرارات والنسب المئوية والأوساط الحسابية والانخرافات المعيارية ذات الصلة بالفترات (X-X نحو الاتفاق على توفر هذا البُعد لدى المشاريع المستجيبة، وتشير النسب إلى أن (68.8 \% من أفراد العينة لدهم اتفاق على مضمون العبارات (X عدم الاتفاق مع هذا التوجه فبلغت (21.6 \%)، وكانت نسبة الحياد (9.6 \%)، وجاء هذا بوسط حسابي مقداره (2.59) وانحراف معياري مقداره (0.65). وهذا يعطي دلالة أولية على أن آراء أفراد العينة متفقة على أن المشاريع المستجيية تعتبر التسويق الريادي هو استغلال الفرص ، وتتييم البيئة التنافسية بشكل مستمر لتقليل حالات عدم التأكد، وكذلك تطوير الاعمال بناءاً على افكر واراء وشكاوى الزبائن، وايضًا طرح خدمات جديدة إلى السوق بشكل مستمر الجدول (2) وصف متغير التسويق الريادي

\begin{tabular}{|c|c|c|c|c|c|c|c|c|}
\hline \multirow{3}{*}{ المعياري } & \multirow{3}{*}{ الحسابي } & \multicolumn{6}{|c|}{ مقياس الاستجابة } & \multirow{3}{*}{ الرمز ل } \\
\hline & & \multicolumn{2}{|c|}{ لاتاتفق } & \multicolumn{2}{|c|}{ محايد } & \multicolumn{2}{|c|}{ أتقق } & \\
\hline & & $\%$ & ت & $\%$ & ت & $\%$ & ت & \\
\hline 0.63 & 2.64 & 20 & 10 & 8 & 4 & 72 & 36 & $\mathrm{X} 1$ \\
\hline 0.70 & 2.58 & 18 & 9 & 12 & 6 & 70 & 35 & $\mathrm{X} 2$ \\
\hline 0.67 & 2.58 & 22 & 11 & 10 & 5 & 68 & 34 & $\mathrm{X} 3$ \\
\hline 0.73 & 2.50 & 22 & 11 & 14 & 7 & 64 & 32 & $\mathrm{X} 4$ \\
\hline 0.55 & 2.66 & 26 & 13 & 4 & 2 & 70 & 35 & X5 \\
\hline 0.65 & 2.59 & \multicolumn{2}{|c|}{21.6} & \multicolumn{2}{|c|}{9.6} & \multicolumn{2}{|c|}{68.8} & الملوشر \\
\hline
\end{tabular}

2.2.5 وصف ابعاد استراتيجيات بورتز العامة

أ- بعد استراتيجية قيادة الكلفة: تشير نتاجُج التحليل المذكورة في الجدول (3) إلى إجابات أفراد العينة في المشاريع المستجيية تجاه وصف بعد استراتيجية قيادة 


\section{5 تحليل علاقة الارتباط بين متغيرات البحث}

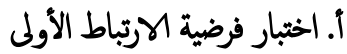

تتناول هذه الفقرة عرضاً لمعاملات الارتباط على المستوى الكلي والجزئي بين التسويق

الريادي واستراتيجيات بورتر التنافسية

على المستوى الكلي يتبين من النتائُ في الجدول (6) وجود علاقة ارتباط معنوية وموجبة بين التسويق الريادي واستراتيجيات بورتر التنافسية وبلغت (0.651) عند مستوى معنوية (0.01)، وهذا يشير الى وجود مستويات معنوية موجبة من التلازم بين التسويق الريادي واستراتيجيات بورتر التنافسية في المشاريع المستجبية. أما على المستوى الجزئي تبين وجود علاقات ارتباط بين متغير التسويق الريادي وأبعاد استراتيجيات بورتر التنافسية المتمثلة بقيادة الكلفة، والتيزي، والتزكيز بمعامل ارتباط بلغ (0.490، 0.657، 0.578) على التوالي عند مستوى معنوية (0.01).فيستنتج من هذا أنه كلما اعتمدت المشاريع المستجيبة على التسويق الريادي فان ذلك يسهم في رفع مستويات أبعاد استراتيجيات بورتز التنافسية لدى تلك المشاريع.

\section{الجدول (6) الارتباط بين التسويق الريادي وابعاد استراتيجيات بورتر الثنافسية}

\begin{tabular}{|c|c|c|c|c|}
\hline \multirow{2}{*}{ المؤشر الكلمي } & \multicolumn{3}{|c|}{ استراتيجيات بورتر العامة } & \\
\hline & التزكيز & التيز & قيادة الكلفة & \\
\hline $0.651^{* *}$ & $0.578^{* *}$ & $0.657^{* *}$ & $0.490^{* *}$ & التسويق الريادي \\
\hline
\end{tabular}

المصدر: إعداد الباحثان بالاعتماد على نتائج التحليل الاحصائي مستوى ومعنوية (0.01) وبالاعتماد على نتاجُُ تحليل علاقات الارتباط السابقة تقبل الفرضية الرئيسية الاولى التي تنص على أنه يوجد ارتباط معنوي ذي دلالة احصائية بين التسويق الريادي و واسترتيجيات بورتز التنافسية على المستوى الكلي في المشاريع الصغيرة والمتوسطة عينة البحث أما على المستوى الجزئي تقبل الفرضية الفرعية الأولى التي تنص على أنه يوجد ارتباط معنوي ذي دلالة احصائية بين التسويق الريادي وقيادة الكلفة للمشاريع

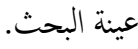

الجدول (4) وصف بعد استراتيجية الثلايز

\begin{tabular}{|c|c|c|c|c|c|c|c|c|}
\hline \multirow{3}{*}{ المنحراف } & \multirow{3}{*}{ الحسابي } & \multicolumn{6}{|c|}{ مقياس الاستجابة } & \multirow{3}{*}{ الرمز } \\
\hline & & \multicolumn{2}{|c|}{ لاتفق } & \multicolumn{2}{|c|}{ محايد } & \multicolumn{2}{|c|}{ أتفق } & \\
\hline & & $\%$ & ت & $\%$ & ت & $\%$ & ت & \\
\hline 0.55 & 2.76 & 12 & 6 & 6 & 3 & 82 & 41 & Y4 \\
\hline 0.78 & 2.56 & 8 & 4 & 18 & 9 & 74 & 37 & Y5 \\
\hline 0.65 & 2.66 & 14 & 7 & 10 & 5 & 76 & 38 & Y6 \\
\hline 0.66 & 2.66 & \multicolumn{2}{|c|}{11.33} & \multicolumn{2}{|c|}{11.33} & \multicolumn{2}{|c|}{77.33} & الكمؤشر \\
\hline
\end{tabular}

المصدر: إعداد الباحثان بالاعتاد على نتائج التحليل الأحصائي

ت- استراتيجية التركيز: تشير ننائج التحليل المذكورة في الجدول (5) إلى إجابات أفراد العينة في المشاريع المستجية تجاه وصف بعد استراتيجية التزكيز التي تمثل التكرارات والنسب المئوية والأوساط الحسابية والانحرافات المعيارية ذات الصلة

بالفقرات (Y, $)$ التي تميل نحو الاتفاق على توفر هذا البُعد لدى المشاريع المستجيبة، وتشير النسب إلى أن (78 \%) من أفراد العينة لدهم اتفاق على مضمون العبارات (Y-Y $)$ أما نسبة عدم الاتفاق مع هذا التوجه فبلغت (18\%)، وكانت نسبة الحياد (4 \%)، وجاء هذا بوسط حسابي مقداره (2.74) وانحراف معياري مقداره (0.49). وهذا يعطي دلالة أولية على أن آراء أفراد العينة متفقة على أن المشاريع المستجبية تعتمد على التركيز في تقديم خدماته على فئة متايزة من الزبائن والتزكيز على جزء معين من السوق لتلبية متطلباته

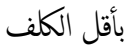

\section{الجدول (5) وصف بعد استراتيجية التركيز}

\begin{tabular}{|c|c|c|c|c|c|c|c|c|}
\hline \multirow{3}{*}{ المنحراف } & \multirow{3}{*}{ الوسط الحسابي } & \multicolumn{6}{|c|}{ مقياس الاستجابة } & \multirow{3}{*}{ 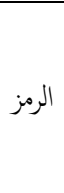 } \\
\hline & & \multicolumn{2}{|c|}{ ل ل ل اتفق } & \multicolumn{2}{|c|}{ محايد } & \multicolumn{2}{|c|}{ أتنقت } & \\
\hline & & $\%$ & ت & $\%$ & ت & $\%$ & ت & \\
\hline 0.30 & 2.90 & 10 & 5 & - & - & 90 & 45 & Y7 \\
\hline 0.65 & 2.68 & 12 & 6 & 10 & 5 & 78 & 39 & Y8 \\
\hline 0.52 & 2.64 & 32 & 16 & 2 & 1 & 66 & 33 & Y9 \\
\hline 0.49 & 2.74 & & & & & & & \\
\hline
\end{tabular}

المصدر: إعداد الباحثان بالاعتاد على نتأج التهليل الأحصائي 
الجدول (7) تأثير التسويق الريادي في استراتيجيات بورتر العامة

\begin{tabular}{|c|c|c|c|c|c|}
\hline للمستمة المحسوبة & قلميمة F Fمسبة & $\begin{array}{l}\text { قيمة } \\
R^{2}\end{array}$ & $\begin{array}{l}\text { قميمة } \\
\text { B }\end{array}$ & قيمة B & الأموذج \\
\hline 0.000 & 35.374 & 0.424 & 0.747 & 0.224 & التسويق الريادي \\
\hline
\end{tabular}

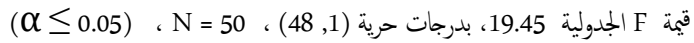
المصدر: إعداد الباحثان بالاعتاد على نتائج التحليل الوحصائي

وبناءاً على النتائج المثبته في الجدول (7) فإنه يتم قبول الفرضية الرئيسة الثانية والتي تنص على أنه يوجد تأثير معنوي ذي دلالة احصائية للتسويق الريادي في استراتيجيات بورتر التنافسية على المستوى الكلي في المشاريع الصغيرة والمثوسطة

$$
\text { عينة البحث }
$$

\section{5 تحليل علاقة الثاثير على المستوى الجزئي}

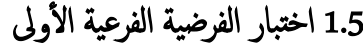

تشير الننائج في الجدول (8) إلى وجود تأثير معنوي للتسويق الريادي في بُعد قيادة الكلفة لاستراتيجيات بورتر التنافسية، إذ بلغت قيمة معامل (t) المسوبة (3.891) وهي أكبر من قيمها الجدولية والبالغة (1.676) وبدرجة حرية (48) مما يشير إلى معنوية الثأثير وعند مستوى (0.05). ويؤكد ذلك أن قيمة مستوى المعنوية المحسوبة والبالغة (0.000)كانت أقل بكثير من قيمة مستوى المعنوية الافتزاضي والذي اعتمدته الدراسة. كما تبين نتاجُ النحليل في الجدول (8) أن قيمة (R2) بلغت (0.240) ، وهذه النتيجة تشير إلى أن ما سبته (24.0\%) من التغير الذي يحصل في استراتيجية قيادة الكلفة يعود إلى المتغير المستقل المتثثل بالتسويق الريادي. وهو يشير إلى وجود عوامل تأثيرية أخرى تبلغ نسبها (76.0\%) غير مضمنة في الأموذج الافتراضي الذي

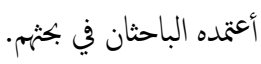

الجدول (8) تأثير التسويق الريادي في استراتيجية قيادة الكلفة

\begin{tabular}{|c|c|c|c|c|}
\hline المعنمة مستوى & قيمة t المحسوبة & قيمة & ق قيمة & الأموذج \\
\hline 0.049 & 2.023 & - & 0.427 & الثابت \\
\hline 0.000 & 3.891 & 0.240 & 0.568 & التسويت الريادي \\
\hline
\end{tabular}

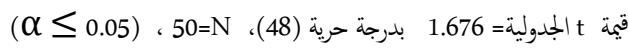

وتقبل الفرضية الفرعية الثانية التي تنص على أنه يوجد ارتباط معنوي ذي دلالة احصائية بين التسويق الريادي والتزكز للمشاريع عينة البحث. تقبل الفرضية الفرعية الثالثة التي تنص على أنه يوجد ارتباط معنوي ذي دلالة احصائية بين التسويق الريادي والنايز للمشاريع عينة البحث.

\section{5 تحليل علاقات الثأثير على المستوى الكلي}

تشير نتاجُ التحليل في الجدول (7) إلى وجود تأثير معنوي للمتغير المستقل والمتمثل بالتسويق الريادي في المتغير التابع والمتمثل باستراتيجيات بورتز التنافسية وعلى مستوى المؤشر الكلي لها، إذ بلغت قيمة معامل (F) المحسوبة (35.374) وهي أكبر من قيمها الجدولية والبالغة (19.48) وبدرجات حرية (1 ، 48) ، مما يشير إلى معنوية الثاثثير وعند مستوى (0.05) وعلى المستوى الكلي لأموذج البحث. ويدع ذلك أن قيمة مستوى المعنوية المحسوبة والبالغة (0.000) كانت أقل بكثير من قيمة مستوى المعنوية الافتراضي والذي اعتمدته الدراسة والبالغ (0.05). كما وتشير ننائج التحليل ضمن هذا المستوى في ضوء معادلة الانحدار توضح قيمة الثابت (B0) والبالغة (0.224) أن هناك ظهوراً لاستراتيجيات بورتز التنافسية من خلال عواملها مقداره (0.224) وذلك عندما تكون قيمة التسويق الريادي ومن خلال ابعاده مساوية للصفر ،وعليه يمكن تفسير هذه النتيجة بأن استراتيجيات بورتر التنافسية تستمد خصائصها بشكل كير من التسويق الريادي في المشاريع المبحوثة، أما قيمة الميل الحدي (B) فقد كانت (0.747) والمرافقة لمتغير استراتيجيات بورتر التنافسية فهي تدل على إن تغيراً مقداره (1) في متغبر التسويق الريادي سيؤدي إلى تغير مقداره (74\%) في استرانيجيات بورتر التنافسية ومن خلال عواملها والممثلة بكل من قيادة الكلفة، والتيايز، والتزكيز وهو تغير جيد يمكن الاستناد عليه في تفسير العلاقة الثأثيرية للمتغير المستقل التسويق الريادي في المتغير المعتمد استراتيجيات بورتر التنافسية.كما تبين نتابُج التحليل في الجدول (7) أن قيمة (R²) بلغت (0.424) ، وهذه النتيجة تشير إلى أن ما نسبته (42.4\%) من التغير الذي يجصل في استراتيجيات بورتر العامة يعود إلى المتغير المستقل والمتمثل بالتسويق الريادي ، وهو يشير إلى وجود عوامل تأثيرية أخرى تبلغ نستها (58.6\%) غير متضمنة في الأنموذج الافتراضي الذي أعتمده

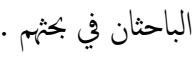


(0.000) كانت أقل بكثير من قيمة مستوى المعنوية الافتراضي والذي اعتمده البحث، كما تبين نناجُج التحليل في الجدول (10) أن قيمة (R2) بلغت (0.334) ، وهذه النتيجة تشير إلى أن ما نسبته (33.4\%) من النغير الذي يحصل في استراتيجية التزكيز يعود إلى المنغير المستقل المتثلل بالتسويق الريادي. وهو يشير إلى وجود عوامل تأثرية أخرى تبلغ نسبتها (66.6\%) غير مضمنة في الأنموذج الافتراضي الذي أعتمده الباحثان في بكثهיه. وبناءاً على النتائُ المثبتة أعلاه فإنه يتم قبول الفرضية الفرعية الثانية والتي تنص على أنه يوجد تأثير معنوي ذي دلالة احصائية للتسويق الريادي في التزكيز للمشاريع الصغيرة والمتوسطة عينة البحث.

الجدول (10) تاثير التسويق الريادي في استراتيجية التركيز

\begin{tabular}{|c|c|c|c|c|}
\hline قيمة مستوى المعنوية & قيمة t المحسوبة & قيمة & ق قيمة & الأموذج \\
\hline 0.035 & 2.174 & - & 0.394 & الثابت \\
\hline 0.000 & 0.911 & 0.334 & 0.615 & التسويق الريادي \\
\hline
\end{tabular}

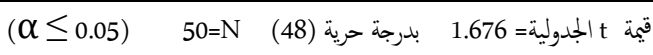
كالمدر: إعداد الباحثان بالاعتاد على نتائج التحليل المحصائي

6. الاستناجات والتوصيات

يعمل المحور الحالي على تسليط الضوء على ننائُ البحث ساعياً نحو النظر اليها نظرة شمولية معمقة تقوم على اساس التحليل والتفسير ، وبغية الخروج بجملة استناجات تمثل الاساس العريض للمعالجات والتوصيات المقترحة.

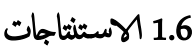

ينظر المى التسويق الريادي كتسويق خاص بالمنظلات الصغيرة التي تتميز بحجم المنظمة وعمها وعلى انه الاستباقية وتحديد واستغلال الفرص بالاعتماد على الابداع واخذ المخاطر والانشطة التسويقية الغير خطية. تبين أن التسويق الريادي في المشاريع المستجيبة بمثل استغلال الفرص وتقييم البيئة التنافسية بشكل مستمر لتقليل حالات عدم التأكد وكذلك تطوير الاعمال بناءاً على افكار واراء وشكاوى الزبائن وايضاً طرح خدمات جديدة الى السوق بشكل مستمر.
المصدر: إعداد الباحثان بالاعتماد على نتائُ التحليل الاحصائي وبناءاً على النتائُ المثبتة أعلاه فإنه يتم قبول الفرضية الفرعية الأولى والتي تنص على أنه يوجد ثأثير معنوي ذي دلالة احصائية للتسويق الريادي في قيادة الكلفة للمشايع الصغيرة والمتوسطة عينة البحث.

2.5 اختبار الفرضية الفرعية الثانية تشير النتائُ في الجدول (9) إلى وجود تأثير معنوي للتسويق الريادي في بعد التمايز لاستراتيجيات بورتر التنافسية ، إذ بلغت قيمة معامل (t) المسوبة (6.033) وهي أكبر من قيمتها الجدولية والبالغة (1.676) وبدرجة حرية (48) مما يثير إلى معنوية الثأثير وعند مستوى (0.05). ويؤكد ذلك أن قيمة مستوى المعنوية المحسوبة والبالغة (0.000) كانت أقل بكثير من قيمة مستوى المعنوية الافتراضي والذي اعتمده البحث، كما تبين نتائج التحليل في الجدول (9) أن قيمة (R2) بلغت (0.431) ، وهذه النتيجة تشير إلى أن ما سبته (43.1\%) من التغير الذي يحصل في استراتيجية التيايز يعود إلى المتغير المستقل المتمثل بالتسويق الريادي. وهو يشير إلى وجود عوامل تأثيرية أخرى تبلغ نسبتها (56.9\%) غير مضمنة في الأموذج الافتراضي الذي أعتمه الباحثان

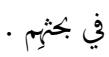

الجدول (9) تأير التسويق الريادي في استراتيجية الثايز

\begin{tabular}{|c|c|c|c|c|}
\hline قيمة مستوى المعنوية & قيمة t المحسوبة & قيمة & قيمة B & الأنموذج \\
\hline 0.560 & -0.587 & - & -0.149 & الثابت \\
\hline 0.000 & 6.033 & 0.431 & 1.057 & التسويق الريادي \\
\hline$(\alpha$ & $50=$ & $(48$ & & : t الجدولية= 676. \\
\hline
\end{tabular}
المصدر: إعداد الباحثان بالاعتاد على نتابُ التحليل الوحصائي وبناءاً على النتائُ المثبتة أعلاه فإنه يتم قبول الفرضية الفرعية الثانية والتي تنص على أنه يوجد تأثير معنوي ذي دلالة احصائية للتسويق الريادي في التزيز للمشاريع الصغيرة والمتوسطة عينة البحث.

\section{5 اختبار الفرضية الفرعية الثالثة:}

تشير النتائج في الجدول (10) إلى وجود تأثير معنوي للتسويق الريادي في بُعد التزكيز لاستراتيجيات بورتر التنافسية ، إذ بلغت قيمة معامل (t) المحسوبة (4.911) وهي أكبر من قيمها الجدولية والبالغة (1.676) وبدرجة حرية (48) مما يشير إلى معنوية التأثير وعند مستوى (0.05). ويؤكد ذلك أن قيمة مستوى المعنوية المحسوبة والبالغة 
ظهر أن المشاريع المستجيبة تعتمد مجموعة من الاجراءات في قيادة الكلفة والتمايز 7. المصادر والتزكيز تتمثل في خفض الكلف وتقديم خدمات استثنائية تبرر ارتفاع الاسعار 1.7 المصادر العربية

1. ادريس، وائل محمد صبحي، الغالبي، طاهر محس منصور،(2016)، الادارة الايتراتيجية

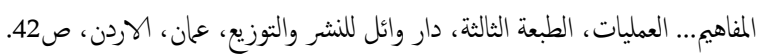
2. اوسو، خيري على(2012)، دور التفكير الابداعي في تحقيق التسويق الريادي، بجلة بولي تكنيك، الججلد (2)، العدد(2) ، جامعة بولي تكنيك، اربيل، العراق، ص29. 3. بارو، كولن،(2018)، ماجستير ادارة الاعمال في التسويق في 30 يوما دليلك السيع للنجاح في الاعمال، الطبعة الاولى، مكتبة جرير للنشر والثوزيع، لسعودية، ص56. 4. البكري، ثامر،(2014)، قضايا معاصرة في التسويق، الطبعة الوولى، دار حامد للنشر والتوزيج،

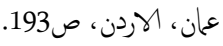
5. بن حمدان، خالد محمد وادريس، وائل محمد صبحي، (2007)، "الاستراتيجية والتخطيط الاستراتيجي منجج معاصر"، دار اليازوري العلمية للنشر والتوزيع، عان، الاردن، ص241. 6. الدعي، علاء فرحان طالب والمسعودي، فاطمة عبد علي سلمان، (2011)،"المعرفة السوقية

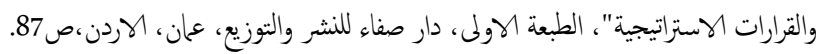
7. السكارنة، بلال خلف، (2014)، "الاستراتيجية والتخطيط الاستراتيجي"، الطبعة الوولى ، دار المسيرة للنشر والتوزيع والطباعة، عان، الاردن،ص266.

8. دراسة تحليلية لآراء عينة من مديري مصارف القطاع الخاص في مدينة اربيل، بجلة الجامعة للعلوم الأنسانية، جامعة صلاح الدين، المجلد(19)،العدد (1). 9. صادق، درمان سليمان، (2010)، قياس مكانة عمليات التسويق الريادي في منظ|ت الكعال الصغيرة ، دراسة استطلاعية في عينة من مصانع المياه المعدنية في اقليم كردستان - العراق،

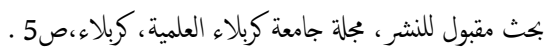

10. الككاكوي، احمد حميد، (2004)، العلاقة بين المناخ التنظيمي والابداع المنظي وتاثيرها في تحتيق الميزة التنافسية، دراسة تطبيقية في عينة من المصارف التجارية العراقية، رسالة ماجستير في ادارة الاعمال، كلية الادارة والاقتصاد، جامعة القادسية ، القادسية، العراق،ص 21. 11. مقري، زكية ويياوي، ننمة،(2015)، "التسويق الاستراتيجي مداخل حديثة"، الطبعة

$$
\text { الاولى، دار الراية للنشر والتوزيع، عان، الاردن، ص } 87 .
$$

12. نجم، عبود، (2003)، ادارة الابتكار، المفاهيم والخصائص والتجارب الحديثة، الطبعة الاولى، دار

$$
\text { وائل للنشر والتوزيع، عان، الاردن،ص42. }
$$

13. سعيد، اممد ممد باقر،(2011)، دور الابداع بالمزيج التسويتي في تعزيز التسويق الرياديدراسة استطلاعية لاراء المديرين في عينة من منظات الوعال الصغيرة في محافظة دهوك، رسالة ماجستير ، فاكلتي القانون والادارة، سكول الإدارة والاقتصاد، جامعة دهوك، العراق. والتزكيز على جزء معين من السوق لتلبية متطلباته بأقل الكلف. توصل البحث الى وجود ارتباط معنوي بين التسويق الريادي واستراتيجيات بورتر التنافسية على المستوى الكلي والجزئي، فيستنتج من هذا أنه كلما تم اعتاد المشاريع المستجيبة على التسويق الريادي فإن ذلك يسهم في رفع مستويات استراتيجيات بورتر التنافسية (قيادة الكلفة، التايز، التركيز) لدى

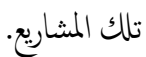
توصل البحث إلى وجود تأثير معنوي للتسويق الريادي في استراتيجيات بورتر التنافسية على المستوى الكلي والجزئي.

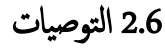
أن تُطور المشاريع المستجيبة خططها واستراتيجياتها وبما يجعلها ذات توجه

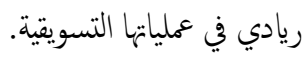
زيادة الاهتمام بكفوم التسويق الريادي في تعزيز استراتيجيات بورتر التنافسية بشكل متكمل من أجل تحقيق أداء متميز على مستوى الاعمال المشاريع والبحث عن حالة النفرد في قيادة السوق. على المشاريع المستجيبة البحث عن اساليب واسترتيجيات جديدة تستطيع من خلالها توليد القيمة لزبائها والذي يعتبر مصدر ربحيته وذلك من خلال تقدييم منتجات جديدة لزبائها وبأسعار منافسة وتسهيل عملية الحصول على المنتج. على المشاريع الصغيرة والمتوسطة رسم الاستراتيجيات التنافسية ووضع الخطط والبرامج التسويقية في تقديم منتجات متميزة تحقق ميزة تنافسية. زيادة الوعي بالتسويق الريادي لدى مدراء المشاريع الصغيرة والمتوسطة الحجم بالدور الذي يلعبه التسويق الريادة في تحقيق الميزة التنافسية للمشروع. اعداد برامج اللندريب التسويتي الذي يتضمن مختلف الانشطة والبرامج التسويقية لمدراء المشاريع الصغيرة والمتوسطة. 
Management, Faculty of Management, University of Peradeniya, Sri Lanka, Vol.5, (Iss.5).

10. Kraus , Sascha,Harms, Rainer,Fink , Mathias , (2009), Entrepreneurial Marketing : Moving beyond Marketing in new ventues, Int.J., Entrepreneurship and Innovation Management , Special Issue .

11. Kraus, Sascha ;Eggers ,Fabian;Harms, Rainer; Hills, Gerald E\& Hultman, Claes,(2011),Diskussionslinien Der Entrepreneurial Marketing-Forschung: Ergebnisse Einer Zitationsanalyse, Journal Of Business Economic,Vol. 81, No. 6.

12. Manu, George and Robert Nelson. 2000. What is Enterprise? Entrepreneurship Education in Vocational and Technical Training, Module (1). International Training Center of ILO, 30-31.

13. Mehran, R. ,Morteza ,K.,(2013), Prioritization of entrepreneurial marketing dimensions: A case of in higher education Institutions by using entropy, Interdisciplinary Journal of Contemporary Research in Business, Vol.4, No.12.

14. Miles, M., \& Darroch, J. (2006), "Large Firms, Entrepreneurial Marketing Processes, and theCycle of Competitive Advantage", European Journal of Marketing, Vol. 40, Nos. 5\&6, pp485-502.

15. Minarik Martina, (2007), " Cost Leadership \& Differentiation - An investigation of the fundamental trade-off between Porter's cost leadership and differentiation strategies", Stockholm School of Economics, Institute of International Business,.

16. Morris, Michael H., Schindehutte, Minet , LaForge Raymond W.,(2002), Entrepreneurial Marketing: A Construct for Integrating Emerging Entrepreneurship and Marketing Perspective, Vol. 10, No. 4 .

17. Nwaizugbo, I. C1 and Anukam, A. I,(2014), Assessment of Entrepreneurial Marketing Practices among Small and Medium Scale Enterprises in Imo State Nigeria: Prospects and Challenges, Review of Contemporary Business Research, Vol. 3, No. 1, pp. 77-98, Website: www.aripd.org/rcbr.
2.7 المصادر الهنبية

1. Abdelrahman,S.O.,(2012), The Impact of Enterepreneurial Marketing Factors of Competitive innovativeness among Female Enterepreneurs in Egypt,thesis,department of Business Administration, Faculty of commerce, Cairo University.

2. Bjerke, B. , Hultman ,C., (2002), EM : The Growth of Small Firms in the new economic era, Edward Elgar, Chelternhum .

3. Bonnet, Jean, \& Le pope, Nicolas, (2008), Successful proactive market orientation of new Enterpreneurs : what kind of Human capital 207 matters? Doctoral track and conference Enterpreneurship, culture, finance and Economic development, 19-20th of Jone.

4. Dwyer, Michele, O.(2009), Entrepreneurial Marketing RENT XXIIIResearch in Entrepreneurial and small business,BUDAPEST, Itunn .Gary,November, http://www.eiasm.org/frontoffice/eventloin.asp.

5. Hills , Gerald E., Hultman , Claes M., (2006), Entrepreneurial Marketing, Form Marketing - Broadning the Horizons by Stefan Lagrosen ,Goran Svensson, Studentlitteratur .

6. Ho, Teck-Hua; Park, Young-Hoon\& Zhou, Yong-Pin, (2006), Incorporating Satisfaction In to Customer Value Analysis: Optimal Investment In Lifetime Value, Journal Of Marketing Science, Vol. 25, No. 3.

7. Jones, Rosalind\& Rowley, Jennifer, (2011), Entrepreneurial Marketing In Small Businesses: A Conceptual Exploration, International Small Business Journal, Vol. 29, No. 1.

8. Josiah Nyauncho M. \& Nyagara Nyamweya,(2015), " Assessment of the effect of Cost Leadership Strategy on the performance of Liquefied Petroleum Gas Companies in Eldoret town, Uasin Gishu County, Kenya" , International Journal of Business and Management Invention, Volume 4 Issue 4,PP-01-07.

9. Kolongahapitiya K.H.M.A.R (2018), Progression of theory of Entrepreneurial Marketing (EM), International Journal of Engineering Technologies and Management Research, Department of Marketing 
18. Pisano V. \& Hitt M., (2015), " Whats competitive strategy? Origins and development of a relevant research area in strategic management", University of Catania,.

19. Tanwar Ritika, (2013), " Porter's Generic Competitive Strategies", Journal of Business and Management (IOSR-JBM), Volume 15, Issue 1, PP 11-17. 
الملحق (1)

م/ استبانة

السيد مدير /مديرة المشروع المحترم

تحية طيبة:

نضع بين ايديك الاستبانة التي أعدت لقياس متغيرات البحث الموسوم التسويق الريادي وأثره في استراتيجيات بورتر الثنافية: مدخل في مدى ادراك مديري المشاريع الصغيرة والمتوسطة الحجم لتلك العلاقة (دراسة ميدانية لأراء عينة من مديري عدد من المشاريع الخدمية في محافظة دهوك) نرجو أن تحظى فقرات الأستبانة باهتمامك وحرصكم الأكيد عند إجابتها تحقيقاً لدقة التحليل وصواب الرأي في نتاجُ البحث، وسيعك هذا الأهمثام تفها ووعياً رفيعين للسعي نحو تعزيز الأطر العلمية والمعرفية للبحث العلمي بكل أبعاده.

علاً ستستخدم إجاباتكم لأغراض البحث العلمي وفي حدود الدراسة الحالية حصرا.

مع فائق شكرنا وقديرنا لتعاونم

الباحثة

الباحث

أولاً: المعلومات العامة

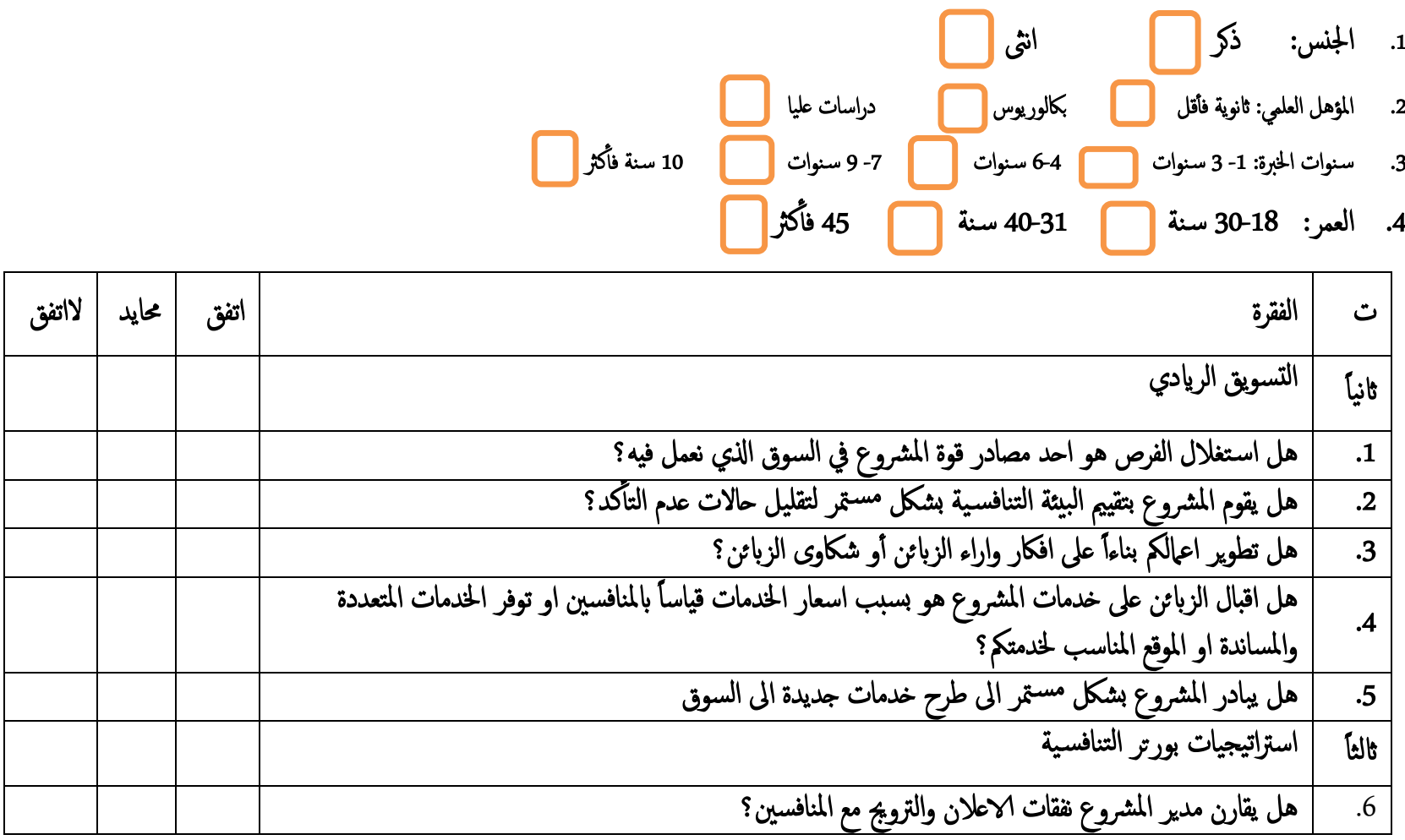




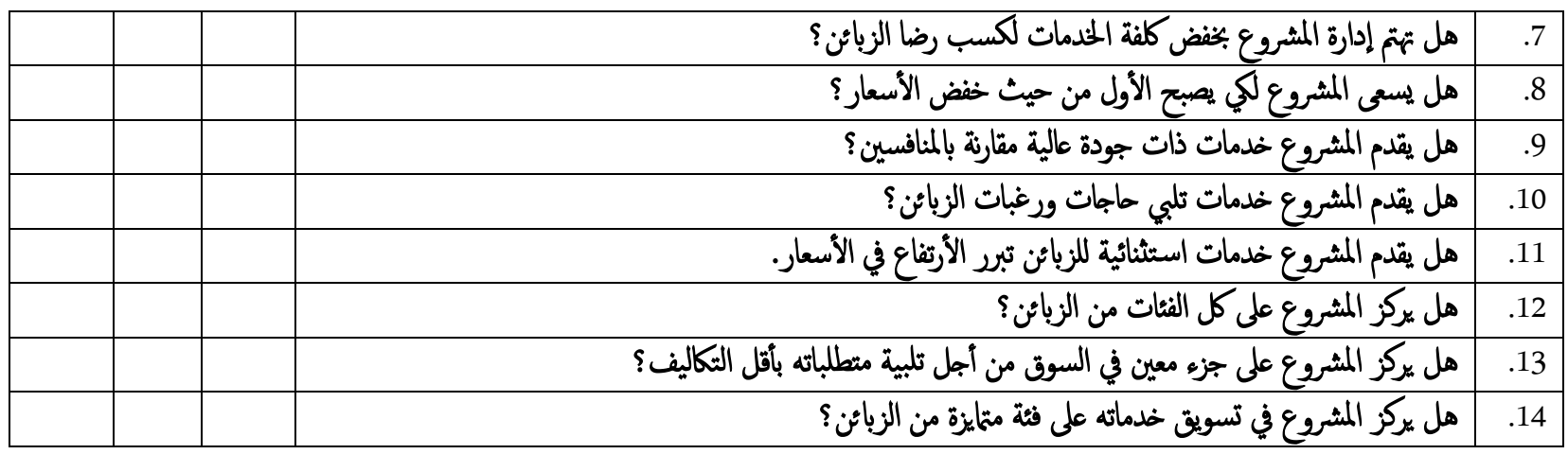

